\title{
Três estratégias para uma mesma experiência estética: em torno do "periférico" na cultura massiva
}

\section{Gelson Santana}

Professor do Mestrado em Comunicação da Universidade Anhembi Morumbi (SP).

\section{Resumo:}

Este artigo se constitui a partir do estudo dos filmes Cidade de Deus, Gomorra e Distrito 9, buscando apontar três estratégias que servem de base ao processo de passagem, de agenciamento e de reestruturação a que um contexto "local" se expõe na sua transformação em "global", nas narrativas audiovisuais contemporâneas construídas em torno da idéia de "periférico". Observa-se de que forma tais estratégias estão diretamente ligadas à experiência estética posta hoje em circulação por uma conjuntura que aparentemente se tornou independente, na medida em que não mais emerge diretamente do espaço social, mas que toma como referente os meios de comunicação massivos.

Palavras-Chave: periférico, estética, filme, local, global.

\section{Abstract}

This article proposes a study on movie films Cidade de Deus, Gomorra [Gomorra] and Distrito 9 [District 9], pointing up three strategies of base (basic strategies) about passage, intermediation and restructuring processes, in which a "local" context exposes its own transformation into a "global" context on the contemporary audiovisual narratives that construct themselves according to the idea of "peripheral" (i.e. "on the outskirts"). We observe how those strategies are straightly associated with a current aesthetic experience, seemingly independent, insofar it no longer emerges from the social space, but from the mass media.

Keywords: peripheral, aesthetics, film, local, global.

$\mathrm{Na}$ atualidade, a consciência coletiva que modela o mundo é modulada, esteticamente, por estratégias que têm por objeto a transformação das representações: de locais em globais (1). Para tanto, os aspectos locais de uma tradição cultural são tornados transparentes, em função de um código difusor que atua de modo independente, com relação às premissas particulares que simbolizam as culturas, quaisquer que elas sejam. 
Assim, o olhar local que, tradicionalmente, determina o ponto de partida de uma narrativa, continua presente. Só que de forma secundária, em função de uma série de operadores globais postos em ação.

Neste sentido, pode-se observar que a idéia localizada de periferia continua funcional nas mídias, mas o conceito de fronteira, que nela se ancora, enfraqueceu-se em função de certos desdobramentos globalizados que os códigos narrativos sofreram ultimamente.

Diante dessa premissa, é interessante notar como a idéia de contexto se faz relativa, se tomada como um operador capaz de modelar as narrativas, na contemporaneidade. Tomando por princípio o ponto de vista da produção, o contexto, agora, pertence ao espaço de circulação das narrativas audiovisuais. Isso quer dizer que o contexto local ficou transparente em relação a um contexto midiático que garante o gerenciamento da economia de circulação de um determinado produto audiovisual. Pode-se dizer que o contexto, hoje, é o meio que faz circular um produto específico ou que cria condições para a circulação de uma rede de produtos audiovisuais.

As condições simbólicas de produção, que costumam determinar a emergência das narrativas, não são mais importantes que as estratégias e as condições de circulação do produto, no campo do audiovisual. Dessa forma, as culturas locais encontram-se descentradas em função de uma única centralidade midiática, capaz de administrar uma experiência global dentro de toda uma circularidade nos meios massivos. As estratégias, então, se fundamentam no processo de converter o que seria manifestamente local em realidade global.

Essa conversão do local em realidade global está presente, incondicionalmente, em três produções cinematográficas nascidas em diferentes contextos e que, no entanto, convergem para uma mesma experiência estética: Cidade de Deus (Brasil, 2002) (2); Gomorra (Itália, 2008) (3); Distrito 9 (Nova Zelândia / África do Sul / EUA, 2009) (4). Tais realizações são exemplos de como algumas narrativas se conformam em função de um feixe de estratégias condicionadas globalmente a partir de um código comum que difunde e modela os elementos particularizados, reconfigurando-os de modo total. É preciso notar que, como parte desse fenômeno de reconfiguração, uma mesma rede de convenções atravessa diversos tipos de produtos midiáticos: do videoclipe aos documentários, passando por séries e telejornais etc. Vistas como estratégia dos meios, essas convenções impermeabilizam a superfície narrativa dos aspectos simbólicos que os componentes locais possam fazer emergir descontroladamente. Isso transforma o "design" de um produto audiovisual em um jogo conduzido por uma espécie de desequilíbrio entre a transparência local e a opacidade global.

Apesar disso, o contexto da experiência estética dessas produções é a configuração do periférico. Nelas podemos observar três táticas capazes de modelar a construção de um lugar midiático para a periferia: uma está proposta no filme Cidade de Deus, outra sugerida em um filme de produção européia, Gomorra, e uma terceira, em um filme de feição híbrida, Distrito 9. Essas três produções contornam a presença da periferia construindo estratégias narrativas diferentes. Não que o tema tenha diretamente a ver com essas diferenças, pelo contrário, há como que uma conjunção entre narrativa e efeito imagético. Nesse sentido, podemos 
estabelecer relações de interdependência entre os modos como os três filmes compõem a periferia enquanto presença de suas narrativas.

No caso de Cidade de Deus, não há distanciamento entre presença e narrativa, elas funcionam como uma coisa só. Em Gomorra, se estabelece um distanciamento entre presença e narrativa, elas procuram ocupar espaços distintos. Já Distrito 9, promove uma estratégia de proximidade e distância entre presença e narrativa.

Em todos os três casos, a ambigüidade impera, seja ela implícita, explícita ou convencionada. No entanto, o caráter residual dessa ambigüidade contorna não apenas a voz off e a câmera usada como uma espécie de testemunha, mas também a consonância entre registrar e mostrar. Essas diferenças fazem da ambigüidade a porta de entrada capaz de transformar certas articulações locais em marcas globais, como se observa nessas produções. Simultaneamente, as múltiplas ambigüidades impossibilitam a emergência dos aspectos simbólicos locais, na medida em que esses aspectos ficam cristalizados na superfície da imagem, que funciona como retentora de uma espécie de arquétipo narrativo. Tudo se passa como se a ambigüidade respondesse diretamente ao campo de uma realidade midiatizada que transforma as divergências representativas locais em uma espécie de repertório globalizado. Por isso, o campo de realidade estética que as mídias impõem, em vez de efeitos simbólicos, produz arranjos e rearranjos de escalas de experiências icônicas capazes de modular, através da ambigüidade, as transições entre o local e global. O resultado das estratégias de convergência do local em global transparece na impossibilidade das narrativas diretas no cinema atual.

Nos filmes da contemporaneidade, a câmera se apresenta sempre mediada por alguma coisa, seja ela virtual ou não, criando uma espécie de cortina de fumaça na experiência direta do mundo. Nos três filmes aqui citados, esse processo indireto administra uma estratégia organizadora da periferia, a qual se oculta como presença direta na narrativa.

O caráter indireto da câmera não está pautado em uma contraposição à estética do cinema direto. Todo processo que transforma a narrativa em artefato indireto, hoje, se relaciona com os diversos tipos de experiência da imagem, com a prática da remissão à imagem, em vez de ao lugar primário de origem dela. Por outro lado, todo processo que determina o campo midiático da narrativa liga-se diretamente a experiências indiretas com o mundo. O espetacular, então, já não é a sensação mediada do mundo, mas as experiências de re-mediação do real a partir de outras realidades (como as interfaces digitais interativas, por exemplo) que põe em segundo plano as realidades simbólicas. Por essa razão, o mundo como experiência primária, atualmente, resulta das tecnologias, sobretudo da digital, que é capaz de modelar outras realidades independentemente da simbólica. Essa independência de uma centralidade simbólica leva a produção não de "outra" realidade, mas de realidades fragmentadas que co-existem na simultaneidade. Elas se multiplicam e se expandem à medida que transformam o viver em uma experiência efetivamente complexa no campo da realidade mediada.

Essa complexidade, oriunda da realidade mediada, ganha relevo à medida que, paulatinamente, no cinema, os personagens saem do primeiro plano da narrativa para se integrar ao espaço lisível da imagem. Os 
personagens não mais emergem de uma realidade simbólica, agora eles pertencem ao contexto da imagem. A potência dos personagens não extrapola a superfície imagética, agora eles são contidos por ela. Estão presos às estratégias que modelam o lugar que eles configuram: parece um paradoxo, mas os personagens se desmaterializaram no cinema contemporâneo. E não só os personagens, mas também as ambiências que os contêm sofrem esse processo de desmaterialização.

Por isso, é possível dizer que a periferia que contorna e abarca os personagens nos filmes Cidade de Deus, Gomorra e Distrito 9 pertence à imagem e não a uma realidade socialmente localizável. Ou seja, nesses três produtos cinematográficos, a ambiência "periferia" é a imagem de uma realidade socialmente localizável, mas convertida em figuração da narrativa.

O filme Distrito 9 joga com dois efeitos simultâneos. Ao mesmo tempo em que dissimula uma narrativa que se esconde atrás de um simulacro de registro documental, conforma-se a uma narrativa ficcional de primeiro grau. A câmera simula o testemunho de uma realidade e simultaneamente constrói esta realidade. $\mathrm{O}$ resultado produz uma ficção que se enreda na própria ficção. A estratégia busca um tom de realismo que hoje pertence aos telejornais diários, ao mesmo tempo em que dissolve este tom na aparência ficcional. Embaralha os discursos em busca do efeito de real, tão caro ao telejornalismo. Isso faz com que a narrativa esteja ao mesmo tempo dentro e fora das estratégias que lhe dão forma.

A descentralização da narrativa converge para o tema do filme ao combinar proximidade e distância, familiaridade e estranhamento ao desenho de um não-lugar que vai ocupar um espaço entre o simulacro de registro da realidade e a busca de um realismo ficcional. É dessa maneira que a brincadeira interna com a ambigüidade temporal faz com que a narrativa, formatada como registro, absorva e sustente as marcas que fazem do filme uma ficção científica. Elas estão apoiadas naquilo que chamarei de efeito "Discovery Channel" (ou "History Channel") ao fazer a ficção científica emergir como realidade midiática combinando uma espécie de distanciamento informativo com a proximidade ficcional.

A marca "documental" também se encontra presente nos outros dois filmes, mesmo que aparentemente de maneira indireta.

Primeiro: pelo caráter declarativo ligado à origem de suas fontes primitivas, pois apesar de o livro Cidade de Deus ser classificado como romance, o autor, Paulo Lins, escreve uma nota ao fim do volume nomeando as fontes das histórias: "Este romance baseia-se em fatos reais. Parte do material utilizado foi extraído das entrevistas feitas para o projeto 'Crime e criminalidade nas classes populares', da antropóloga Alba Zaluar, e de artigos nos jornais O Globo, Jornal do Brasil e O Dia” (LINS, 1997: 549).

Segundo: por ter como argumento um livro-reportagem lançado no Brasil com o título Gomorra $-a$ história real de um jornalista infiltrado na violenta máfia napolitana (5). 
No primeiro caso, a narrativa "baseada em fatos reais" toma a feição literária; no segundo caso, trata-se de uma reportagem, ou seja, algo que carrega em si, como condição básica, supostos elementos concretos da realidade.

Se os dois argumentos anteriores apresentam um movimento de passagem transitivo no processo de sua transformação em filme, o terceiro, Distrito 9, faz o argumento emergir, de forma intransitiva, através do estoque de fragmentos narrativos acumulados pelos meios.

Distrito 9, dirigido e co-roteirizado pelo sul-africano Neill Blomkamp (6), se conforma a esse estoque quando ajusta seu período narrativo ao momento áureo da luta contra o apartheid e a libertação de Nelson Mandela. O filme trabalha com o estoque de discursos acumulado pelas mídias e tornado senso comum, através dos mais diversos tipos de reiterações.

Se, por um lado, o filme reflete uma experiência vivida do diretor: "até 1994 [fim do apartheid], Johannesburgo era uma cidade militarizada, armas em todos os lugares e muita presença da polícia, como esses veículos brancos que fazem patrulha por 'Distrito 9'” (Fernanda Ezabella, “'Distrito 9' mistura ficção científica com ‘favela movie' na África do Sul”, Folha de S. Paulo, 20 de setembro de 2009), por outro,

é como um "X-tudo" feito com todos os mitos da ficção científica - Frankenstein, o "ET" de Spielberg, o "Robocop" de Paul Verhoeven, o "Fantasma da Ópera", a multinacional desumana de "Blade Runner", até mesmo os "yahoos" de Jonathan Swift! - empacotados numa espiral rocambolesca que somente ganha interesse conforme se torna mais despropositada e excessiva (Otavio Frias Filho, “'Distrito 9' é 'X-tudo' da ficção científica”, Folha de S. Paulo [Ilustrada], 16 de outubro de 2009).

$\mathrm{Ou}$

só pode ser reconhecido pela improvável soma de suas referências, não em sua integridade. Pense em "Alien - O Oitavo Passageiro" (1979), mais "Cidade de Deus" (2002), mais a série de TV "The Office". Mesmo (...) truncado pelo excesso de temas (racismo, opressão, poder, propaganda, choque cultural) e acúmulo de citações (desde "A Mosca" até "Transformers"), "Distrito 9" é um feito (Ricardo Calil, "Filme de ET deixa reflexão política de lado, mas é eficaz", Folha de S. Paulo [Ilustrada], 16 de outubro de 2009).

Mesmo diante da capacidade de isolar do oceano da realidade midiática esses elementos, o filme Distrito 9 não parte diretamente de outro lugar da experiência, na medida que deixa em segundo plano qualquer intenção com contornos simbólicos (de alguma forma ainda presentes em Cidade de Deus e Gomorra).

Ainda que na primeira realização o espaço local esteja na mão do diretor e co-roteirista, através de sua experiência direta na ambiência do ghetto, os outros dois filmes - tanto o de um diretor paulista (Fernando 
Meirelles), quanto o de um diretor romano (Matteo Garrone) - estão longe de um acesso à experiência narrada enquanto um acontecimento vivido.

Desse modo, por inversão, se de um lado, em Distrito 9 o efeito imediato a ser buscado está em mergulhar o tema do periférico em uma atualidade midiática; de outro, em Cidade de Deus e Gomorra, o objetivo é fazê-lo emergir de uma realidade midiática.

Distrito 9 simula a presença dessa experiência local através de uma estratégia documental na narrativa (7). Já o filme brasileiro e o filme italiano partem de argumentos instanciados em uma realidade fenomenal já codificada como narrativa escrita para configurá-la em imagem. Eles retornam ao espaço local, a partir da realidade midiática. Se a estratégia está na transformação da experiência local em experiência global, a contraestratégia é fazer emergir da realidade midiática a experiência local. No entanto, apesar dessas divergências, os três filmes convergem para o mesmo ponto, na medida em que usam o documental (seja ele testemunhal, vivencial ou vivencial-testemunhal) como ponto nodal e como estratégia para acentuar ou sublinhar o periférico.

Nos três casos, a deriva documental não se sobrepõe ao caráter encenado, ou ainda, ao modo ficcional. Esse "documental" talvez se articule diretamente ao imaginário televisivo (que é aquele de um estado de constatação permanente) como forma de criar uma ambiência capaz de tornar verossímil, ou naturalizar, a história contada.

Dessa forma, a estratégia do ficcional está em tornar-se verossímil a ponto de ser capaz de se fazer articular por essa aparência do documental. Por isso, a temporalidade dos acontecimentos desaparece em razão de uma crônica do estado das coisas. Essa crônica elimina qualquer distância entre acontecimentos passados e a situação atual. Isso porque, mesmo datada, a tática da imagem é tornar atual qualquer acontecimento no espaço da realidade midiática. Até porque, no espaço da globalidade, a "verdade" é fruto das diversas estratégias de reiteração que acabam por naturalizar os acontecimentos. Por isso, toda presentificação emerge da "naturalização" a que está exposta a passagem do local ao global, ou vice-versa. Nesse percurso virtual, o imaginário da distância se dissolveu na proximidade, assim como o imaginário da proximidade se diluiu na distância.

Desse modo, o jogo entre passado e presente na narrativa é implícito e não explicito, pois resulta do efeito de certa indiferença entre o ficcional e o documental como forma de registro do mundo. E é justamente esta indiferença que propicia a sensação de não-lugar das narrativas contemporâneas, como medida para seu efeito global. De qualquer maneira, isso torna transparente a articulação local que dá movimento e representação a esses filmes. Só que, nos três filmes citados, essa articulação pertence à primeira camada da narrativa, ao funcionar como uma espécie de engate para as demais, apesar de apenas figurar e de não se fazer explicitamente presente. 
Em muitos casos, todas as possíveis camadas fílmicas acabam por se fundir com uma representação espetacular. Isso faz com que certos modos simbólicos que tornam localizadas determinadas representações deixem de ter efeito. O que propicia justamente a fusão das camadas pelo efeito-espetáculo é a impossibilidade de um distanciamento explícito do tema.

No caso de Cidade de Deus, por exemplo, tal efeito se confunde com as estratégias narrativas e os processos de imagificação. Resulta que o espaço da reflexão é reduzido ao da reação como em um videoclipe: os dois se tornam uma só coisa. A história contada se confunde com o modo como está sendo contada. Não se diferencia porque, na verdade, não se configura um espaço simbólico entre o que é narrado e os modos e as estratégias de narração. Isso pode ser notado de forma explícita no prólogo do filme (ver LYRA, 2007: 15-25).

Por sua vez, o distanciamento entre encenação e narrativa, em Gomorra (8), nos permite observar o desaparecimento das ideologias que implicitamente preencheriam esse espaço. Evidentemente, não é um certo tom de neutralidade que preenche esse distanciamento, na medida em que há esta incapacidade de simbolizar na narrativa contemporânea. Mas o que preenche é uma espécie de meta-imagem que tem sua base em uma espécie de iconicidade (9) como convenção que substitui qualquer modelo simbólico. Essa iconicidade criou uma espécie de pacto global. Dessa forma, sua constituição é inteligível globalmente. Esse modo implícito de convencionar as narrativas se torna possível na medida em que os códigos tecnológicos que assentam as imagens se repetem e se traduzem em meios diferentes.

Isso converge para uma prática das visualidades que torna invisível, em primeira instância, as formas ideológicas que modelam as imagens. Em certo sentido, o conceito de espetáculo e todas as propostas estéticas daí decorrentes estão calcados na emergência destas estratégias. Naturalizar as imagens e a sua produção pela modelação e re-modelação em diferentes meios é fazer emergir para um primeiro plano seus determinismos tecnológicos que atendem diretamente ao senso icônico como garantia de um novo estatuto ideológico capaz de se colocar no mesmo lugar dos efeitos simbólicos.

O três planos de enredamento do periférico que cobrem, na verdade, os temas de Cidade de Deus, Gomorra e Distrito 9 representam estratégias que atingem localidades distintas: a) a imagem como principal plataforma; b) uma distância indicial entre mostração e narrativa; c) o embaralhamento das estratégias tornado indiferente dentro e fora da narrativa.

No primeiro caso, estamos o tempo todo dentro da narrativa; no segundo caso, estamos o tempo todo fora da narrativa; no terceiro caso, entramos e saímos o tempo todo da narrativa.

Em Cidade de Deus ficamos presos como dentro de uma caixa; em Gomorra, não penetramos essa caixa; em Distrito 9, a caixa se transforma em uma faixa de moebius, estamos ao mesmo tempo dentro e fora, ao mesmo tempo compromissados e descompromissados, ou seja, habitamos um lugar sem lugar, um fora de lugar que se articula a partir de um não-lugar. 
Paradoxalmente, os três modos de contornar o periférico produzem contextos diferentes. No entanto, eles não estão desconectados um dos outros. Apenas determinam diferentes estratégias de organização do mesmo lugar, de construir/desconstruir a oposição entre centro e periferia. Evidentemente, essa oposição emerge como efeito de uma marginalidade, apurada por uma descentralização que toma o centro como o espaço da normalidade.

Pode-se dizer que o periférico se justifica enquanto lugar capaz de espelhar o centro, ao gravitar em torno de uma ética que se oferece como ideal, apesar de simular tão somente uma convenção. Para tanto, aprimora uma estética que tem por função tornar presente o representado como periférico. Cidade de Deus, Gomorra e Distrito 9 portam três formas estéticas de marginalidade que convergem para o ideal espetacular da periferia.

Os valores "humanistas" buscados por esses três filmes pertencem a um lugar que o campo da realidade midiática não é capaz de reconhecer. Na verdade eles pertencem a uma experiência expressiva no qual o fluxo das ideologias ainda ocupava o espaço da experiência local. A procura por estes valores talvez seja um sintoma da primeira década do séc. XXI capaz de apontar para a decadência de muitos dos valores expressivos que reinaram no séc. XX, mas ainda presentes em certos imaginários artísticos contemporâneos. Essa presença é, na verdade, restos de poeira de um humanismo impossível de ser reavido na medida em que o passado habita um presente que só pode ser atualizado, mas não recuperado.

Nos três filmes, a presença de qualquer senso de denúncia é desproposital. Em vez de mostrar-se o quanto o humano vem se degradando nestes tempos atuais, encena-se a falta de lugar para o humano. Enfim, testemunha-se que a experiência cultural e estética dos meios põe em circulação um contexto que não pertence mais diretamente ao espaço social, mas que foi se deslocando desse primitivo lugar de produção para um referente que pertence aos meios de comunicação massivos.

\section{Notas}

Artigo apresentado no GT Estéticas da Comunicação, da XIX Compós, realizada no Rio de Janeiro em junho de 2010 .

(1) “'1984’ não é apenas o título da distopia de George Orwell. É a data em que se desencadeia a desregulamentação das telecomunicações e das bolsas, cuja onda de choque vai se propagar por todo o globo. O presidente Ronald Reagan muda a distribuição da comunicação mundial abrindo as redes à concorrência, desse modo precipitando a corrida às megafusões no setor (...) Se há a confluência rumo a um estilo de via global, é porque os consumidores interiorizaram o universo simbólico elaborado desde o fim da Segunda Guerra Mundial pelos anúncios publicitários, pelos filmes, pelos programas de televisão, mas especialmente aqueles que provinham dos Estados Unidos, promovidos explicitamente como vetores de um novo universalismo" (MATTELART, 2005: 91-93).

(2) Título original: Cidade de Deus. Direção: Fernando Meirelles. Co-direção: Kátia Lund. Roteiro: Bráulio Mantovani, baseado em romance de Paulo Lins. Produção: Walter Salles. Fotografia: César Charlone. Edição: Daniel Rezende. Elenco: Matheus Nachtergaele, Seu Jorge, Alexandre Rodrigues, Leandro Firmino da Hora, 
Roberta Rodrigues, Phellipe Haagensen, Jonathan Haagensen, Douglas Silva, Jefechander Suplino, Alice Braga, Emerson Gomes, Édson Oliveira, Luis Otávio, Maurício Marques, Gero Camilo, Graziella Moretto, Micael Borges.

(3) Título original: Gomorra. Direção: Matteo Garrone. Roteiro: Maurizio Braucci, Ugo Chiti, Matteo Garrone, Massimo Gaudioso, Roberto Saviano e Gianni Di Gregoria, baseado em livro de Roberto Saviano. Produção: Domenico Procacci. Fotografia: Marco Onorato. Edição: Marco Spoletini. Elenco: Salvatore Abruzzese, Simone Sacchettino, Vincenzo Altamuro, Italo Renda, Gianfelice Imparato, Maria Nazionale, Carlo Del Sorbo, Vincenzo Bombolo, Toni Servillo, Carmine Paternoster, Salvatore Cantalupo, Alfonso Santagata, Salvatore Striano, Vincenzo Fabricino, Salvatore Ruocco.

(4) Título original: District 9. Direção: Neill Blomkamp. Roteiro: Neill Blomkamp e Terri Tatchell, baseado no curta-metragem Alive in Joburg (2005), de Neill Blomkamp. Produção: Peter Jackson. Fotografia: Trent Opaloch. Edição: Julian Clarke. Elenco: Sharlto Copley, Jason Cope, Nathalie Boltt, Sylvaine Strike, Elizabeth Mkandawie, John Summer, William Allen Young, Greg Melvill-Smith, Nick Blake, Jed Brophy, Louis Minnaar, Vanessa Haywood, Marian Hooman, Vittorio Leonardi, Mandla Gaduka, Johan van Schoor, Stella Steenkamp, Tim Gordon, Hlengiwe Madlala.

(5) O jornalista napolitano Roberto Saviano publicou o "romance de não-ficção" (segundo o jornalista Sérgio Rizzo) Gomorra - viaggio nel impero economico e nel sogno di domínio della Camorra originalmente em 2006, pela editora italiana Mondadori. O filme de Matteo Garrone procura manter-se fiel a forma direta e sem rodeios do livro.

(6) A origem do filme Distrito 9 é o curta-metragem, de pouco mais de 6 min., Alive in Joburg, produzido no Canadá e rodado em Johanesburgo (África do Sul) em 2005, com direção e efeitos visuais de Neill Blomkamp. Ver: http://www.youtube.com/watch?v=ZlgtbEdqVsk\&feature=player_embedded

(7) "Muitas das entrevistas vistas no filme são bem reais e falam de uma África do Sul que vai além da relação mais óbvia com o apartheid". Neil Blomkamp "entrevistou sul-africanos pobres de Soweto sobre o que eles achavam dos 'illegal aliens', que, em inglês, significa tanto 'alienígenas ilegais' como 'imigrantes ilegais'. Como não sabiam do filme, os entrevistados soltavam o verbo contra os zimbabuanos que passaram a imigrar em massa para a África do Sul nos últimos dez anos, fugidos da ditadura de Robert Mugabe e povoando as favelas do país vizinho" (Fernanda Ezabella, “'Distrito 9' mistura ficção científica com 'favela movie' na África do Sul”, Folha de S. Paulo, 20 de setembro de 2009).

(8) “A maneira de narrar de [Matteo] Garrone não nos leva, como nas concepções clássicas, de fora para dentro dos acontecimentos. Começamos fora e terminamos fora, como se o objetivo do filme fosse, precisamente, o de produzir estranhamento, impedir nossa familiaridade com tal objeto" (Inácio Araújo, "Diretor italiano evita denúncia fácil e filma mundo estranho", Folha de S. Paulo, 19 de dezembro de 2008).

(9) Penso na iconicidade como um efeito das tecnologias atuais centradas na imagem. A predominância das tecnologias da imagem colocou em segundo plano as tecnologias gráficas, ou se confunde com elas. Essa predominância permitiu outras formas de imaginário capazes de descentrar uma construção de mundo antes centrada no simbólico. Isso porque se pode observar que o indivíduo fez-se excêntrico em relação a si mesmo. A necessária centralidade do imaginário simbólico tornou-se secundária em função do excêntrico do imaginário construído pelo efeito icônico.

\section{Referências bibliográficas}

BAUMAN, Zygmunt. Ética pós-moderna. $3^{\mathrm{a}}$ ed. São Paulo: Paulus, 2006.

BECKER, Howard S. Falando da sociedade - ensaios sobre as diferentes maneiras de representar o social.

Rio de Janeiro: Zahar, 2009. 
BOURDIEU, Pierre. As regras da arte - gênese e estrutura do campo literário. São Paulo: Companhia das Letras, 1996.

DE VENTÓS, Xavier Rubert. Teoria de la sensibilidad. 3ª ed. Barcelona: Península, 1979.

HABERMAS, Jürgen. "Modernidade - um projeto inacabado”. In: ARANTES, Otilia Fiori \& ARANTES, Paulo Eduardo. Um ponto cego no projeto moderno de Jürgen Habermas. São Paulo: Brasiliense, 1992, pp. 99-123.

JULLIEN, François. O diálogo entre as culturas - do universal ao multiculturalismo. Rio de Janeiro: Zahar, 2009.

LINS, Paulo. Cidade de Deus. São Paulo: Companhia das Letras, 1997.

LYRA, Bernadette. "Possíveis reverberações - a palavra, a escrita, o som e a imagem”. In: TAVARES, Mirian \& SOARES, Ana Isabel (orgs.). É perigoso debruçar-se para dentro-ensaios sobre cinema e literatura. Braga (Portugal): Pena Perfeita, 2007, pp. 15-25.

MATTELART, Armand. Diversidade cultural e mundialização. São Paulo: Parábola, 2005.

MEIRELLES, Fernando \& MANTOVANI, Bráulio. Cidade de Deus - roteiro do filme. Rio de Janeiro:

Objetiva, 2003.

PERNIOLA, Mario. Do sentir. Lisboa: Presença, 1993.

SAVIANO, Roberto. Gomorra - a história real de um jornalista infiltrado na violenta máfia napolitana. Rio de Janeiro: Bertrand Brasil, 2008.

WARNIER, Jean-Pierre. A mundialização da cultura. $2^{\mathrm{a}}$ ed. Bauru: EDUSC, 2003. 